artigo $]$

[LAURA ZAMBRINI]

Doutora em Ciências Sociais e socióloga pela Universidade de Buenos Aires (UBA). Pesquisadora CONICET. Professora titular de Sociologia da Moda (FADU-UBA).

E-mail: laura.zambrini@gmail.com

\title{
Olhares sobre moda e design a partir de uma perspectiva de gênero*
}

\author{
Miradas sobre moda y diseño \\ desde una perspectiva de género
}

Perspectives on fashion and design from a gender perspective

[resumo] Os estudos de gênero discutem os modos de construção do conhecimento de diversas disciplinas. No entanto, essa perspectiva tem sido pouco presente no ensino e nos discursos que legitimam o design. Estudar a moda a partir de uma perspectiva de gênero permite entender a relação histórica entre os discursos da modernidade industrial, a história da vestimenta e a produção social das sexualidades e dos gêneros em termos binários. Aqui, procura-se estabelecer uma leitura crítica do campo do design e da moda do ponto de vista social e do cultural. Analisam-se como as projeções de gênero impactam no processo de design, no uso e na leitura dos objetos. Também se faz referência à crítica do feminismo ao legado do movimento moderno e à retórica da neutralidade no campo do design.

\section{[palavras-chave}

\section{gênero; moda; cultura; design.}

[resumen] Los estudios de género discuten los modos de construcción del conocimiento de diversas disciplinas. Sin embargo, esta perspectiva ha estado poco presente en la enseñanza y en los discursos de legitimación del diseño. Estudiar la moda desde una perspectiva de género permite entender la relación histórica entre los discursos de la modernidad industrial, la historia de la vestimenta y la producción social de las sexualidades y los géneros en términos binarios. Aquí se busca establecer una lectura crítica del campo del diseño y la moda desde el punto de vista cultural. Se analiza cómo las proyecciones de género impactan en el proceso de diseño, en el uso y la lectura de los objetos. También se hace referencia a la crítica feminista al legado del movimiento moderno y la retórica de la neutralidad en el campo del diseño.

[palabras claves] género; moda; cultura; diseño. 
[abstract] Gender studies discussed ways of building knowledge from various disciplines. However, this perspective has been little present in teaching and in the speeches of design. Study fashion from a gender perspective helps to understand the historical relationship between the speeches of industrial modernity, the history of dress and social production of sexualities and genders in binary terms. Here we seek to establish a critical reading of the field of design and fashion from the cultural point of view. It analyzes how gender impacts the design process, the use and reading of objects. Also, is made reference to the feminist critique to the legacy of modern movement and the rhetoric of neutrality in the field of design.

[keywords] gender; fashion; culture; design.

Os estudos de gênero debatem as formas de construção do conhecimento em diversas disciplinas. No entanto, historicamente essa perspectiva tem sido pouco presente no ensino e nos discursos de legitimação do design e da moda. Contudo, este artigo surge de anos de trabalho de pesquisa na área dos estudos de gênero, mas também porque há vários anos eu dou aulas de sociologia da moda na Universidade de Buenos Aires (UBA), na Argentina. Nesta viagem através das aulas, todos os anos a mesma situação se repete: dezenas de mulheres no curso e apenas três, quatro ou cinco homens dispostos a estudar moda e design. A cada ano eu me pergunto a causa dessa disparidade e por que, se existem tantas designers, no entanto, geralmente, os designers alcançam maior reconhecimento. Ou seja, essa situação me convida a refletir sobre a questão de gênero e como, muito precocemente na carreira universitária, expressaram-se as hierarquias no âmbito do design e da moda.

A integração de um olhar que enfatiza a perspectiva de gênero em uma disciplina nos permite estabelecer as ferramentas apropriadas para compreender, criticamente, em primeiro lugar, a formação sociocultural dos estereótipos de gênero; e, em segundo lugar, as hierarquias históricas entre homens e mulheres, entendidas como hierarquias de poder, que posicionaram de forma desfavorável o feminino no sentido amplo.

Com essas premissas, o objetivo geral do presente artigo é propor uma reflexão teórica com a finalidade de discutir os campos da moda e do design a partir de uma perspectiva de gênero. Por um lado, essa perspectiva pode desestabilizar as certezas culturais que jogaram contra as mulheres em termos simbólicos e materiais (LAMAS, 1995) e, por outro, ajuda a desnaturar o sexismo que acontece nos campos acadêmicos e profissionais do design, que têm colocado a produção de objetos como neutros, ou seja, despojados de todo relacionamento histórico e social.

Definir o projeto de design como um modo de produção cultural supõe que ao projetar uma peça de vestuário, tacitamente, também se está projetando o gênero. Nesse sentido, a moda pode ser uma excelente área de reflexão acadêmica sobre o complexo processo de construção social das identidades de gênero (ZAMBRINI, 2010). Em primeiro lugar, a moda nos convida a perguntar sobre os usos sociais das roupas de acordo com cada momento histórico, em segundo, a moda também permite refletir sobre os significados do vestir do ponto de vista cultural. J. Entwistle caracteriza a relação "corpo e vestir" como "práticas corporais no contexto" porque, segundo a autora, se falamos de roupas, implicitamente falamos sobre corpos vestidos que estão no contexto sociocultural (ENTWISTLE, 2002, p. 24). No entanto, esses contextos não são neutros, eles são cruzados por múltiplas variáveis sociais. Seguindo essa linha, podemos dizer que o vestido outorga significados culturais ao corpo que se referem à classe social e à estética, mas também aos gêneros.

\section{Gênero e moda}

A moda como uma forma privilegiada de organização do vestir é baseada na mudança periódica de vestuário e na inovação constante dos estilos para fins estéticos e de distinção social (MARTíNEZ BARREIRO, 1998). Desde o início da sociedade 
industrial, a burguesia formada como um grupo dominante organizou e instituiu a sistematização do vestir para maximizar os lucros e transformar o fenômeno da moda em uma das indústrias mais rentáveis até o presente. Essa organização do vestir, nascida no fim do século XVIII, é chamada de sistema de moda. Este sistema teve o seu auge no século XX com o consumo de massa (SAULQUIN, 1990). A divisão de trabalho foi uma caracteristica fundamental porque, na era industrial, o trabalho artesanal e sua dimensão criativa tenderam a desaparecer para abrir espaço aos processos produtivos fragmentados e orientados para fabricar produtos estandardizados. 0 sistema de moda, do ponto de vista tecnológico, foi caracterizado pela consolidação do setor por meio da utilização de máquinas industriais e a consequente proliferação das oficinas de têxteis em cidades. Isso facilitou a produção de vestuário de baixa qualidade e de baixo preço/custo que foi distribuída maciçamente nas grandes lojas.

Do ponto de vista sociológico, as práticas do vestir podem ser entendidas como práticas culturais. Portanto, o design e a moda envolvem comunicar certo olhar sobre o mundo. No entanto, esse olhar não é neutro nem abstrato, porque qualquer objeto projetado é inserido no contexto social cheio de valores e história. As roupas têm cargas simbólicas e representações de gênero construídas historicamente e se referem a um conjunto de crenças sobre o feminino e o masculino. Como a maioria dos campos sociais, o campo da moda tem uma herança histórica e cultural que superestima 0 masculino em detrimento do feminino.

A título de ilustração, tarefas como costurar, tecer e bordar, entre outras, são atividades que historicamente têm sido ligadas ao universo feminino e às mulheres. Com efeito, essas práticas foram consideradas atributos morais necessários de qualquer boa esposa, mãe e dona de casa por um longo tempo.

$\mathrm{Na}$ origem da sociedade industrial, o trabalho das mulheres como costureiras na indústria têxtil foi inúmeras vezes invisivel sob a figura dos estilistas, designers e alfaiates. Eles carregavam o prestígio simbólico e material. No século XIX e início do século $X X$, nas fábricas têxteis, as costureiras trabalhavam muitas horas sem reconhecimento e pagamento adequado. A redistribuição de renda, o capital e as condições do trabalho faziam referência à ordem do público, portanto, deixavam de fora as mulheres que eram confinadas ao mundo doméstico.

Algumas das primeiras reivindicações feministas lutavam contra essa configuração injusta do patriarcado e, ao mesmo tempo, denunciavam a construção da representação das mulheres como objeto de desejo para o olhar masculino (BOURDIEU, 1998; SCOT, 2012). Nesse sentido, o feminismo procurou expandir a noção de cidadania para negociar os espaços de poder que caracterizavam as mulheres como objetos de decoração, frágeis e reprodutivos.

Essa chamada divisão arbitrária entre o público e o privado também se manifestou na criação do campo do design. Como quase todos os espaços sociais, o design teve uma predominância masculina simbólica também expressada na Escola Bauhaus. Lá, tiveram uma clara política sexista no que se relaciona à participação das mulheres nas aulas. Ou seja, praticamente não foram aceitas nas aulas de arquitetura ou design industrial, ao passo que foram incentivadas a ter aulas de tecelagem, bordados e cerâmica, entre outras tarefas, por serem consideradas alinhadas com as expectativas sociais do papel das mulheres (VALDIVIESO, 2014). Walter Gropius, o diretor da Bauhaus, não desejava uma feminização da sua escola, portanto, era incompatível com o desenvolvimento de estudos da moda. Isso explica em parte porque, na Bauhaus, não foram feitos vestidos (HERVÁS y HERAS, 2015). Contudo, os preconceitos de gênero se manifestavam na produção do design. 0 vestido foi associado com o feminino e, assim, desqualificado como objeto legítimo do design.

\section{Debater o cânone}

Naquele contexto, existia um forte desapreço pelas mulheres porque elas não eram as protagonistas da mudança social que a Escola Bauhaus desejava'. Em termos 
gerais, o feminismo foi um movimento que articulou o acadêmico e o político para questionar o lugar subordinado que as mulheres tiveram na ordem social moderna caracterizado pela supremacia do olhar masculino sobre o mundo e o patriarcado. Essa preeminência masculina também se manifestou no campo do design.

Embora o feminismo não possa ser definido como um movimento social homogêneo nem como um corpo teórico unificado, ao longo de sua história, os diversos conceitos com os quais se pensaram a relação de poder entre homens e mulheres levaram a diferentes interpretações e olhares. Em poucas palavras, muitas vezes se resume a história do feminismo em termos de "ondas" (GAMBA, 2007, p. 144). Ou seja, a primeira onda feminista foi caracterizada pelo movimento sufragista e cidadão surgido após a Revolução Francesa. Olympia de Gouges, na França, e Mary Wollstonecrafft, na Inglaterra, foram as principais referências. Elas lutavam pelo reconhecimento das mulheres como cidadãs, pelo direito ao voto e pelo acesso à educação formal.

A segunda onda teve como aporte principal desnaturalizar a categoria mulher para pensá-la como categoria social, e não natural. Simone de Beauvoir é vista como sua maior representante: sob a influência do existencialismo francês, ela sugeriu pensar o gênero como uma construção social. Além disso, a segunda onda foi influenciada pelas contribuições de feministas americanas, como Betty Friedan e Carol Hanish, na década de 1960. Elas denunciaram a opressão e o descontentamento experimentado por mulheres "donas de casa" no contexto pós-Segunda Guerra Mundial. Entre outras coisas, o confinamento da vida na casa, a impossibilidade do desenvolvimento no mundo do trabalho, o imperativo do casamento e a maternidade como destinos inevitáveis das mulheres abriram espaço para o nascimento do slogan "o pessoal é político", que propõe pensar a falsa dualidade na vida pública e privada.

É importante observar que tanto a primeira quanto a segunda onda do feminismo não conseguiram quebrar o pensamento binário da racionalidade moderna, estabelecendo de alguma forma uma visão essencialista ao projetar a identidade. Considera-se também que essas teorias apenas questionam a vida das mulheres brancas e burguesas, isto é, têm sido teorias valiosas, mas com fortes preconceitos sociais e raciais.

A renovação teórica e conceitual que permitiu a quebra das grandes categorias modernas para pensar os problemas de identidade de gênero veio com as contribuições do feminismo da terceira onda. Essa corrente se perguntou pelas características do sujeito político do feminismo, considerando não apenas o sexo, mas também o corpo como produção cultural e histórica. Ou seja, foi possivel remover a relação entre sexo e gênero a partir da incorporação da virada performativa proposta por J. Butler (2001) para pensar as relações históricas dos gêneros.

Como se pode perceber, a ligação entre o feminismo da terceira onda e o pensamento pós-estruturalista permitiu a definição de novas ferramentas conceituais que são substantivas para abordar e compreender as posições do sujeito feminino no

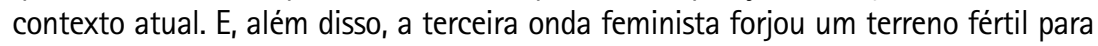
a inclusão de outras categorias que anteriormente tinham sido deixadas de fora das questões de gênero. Por exemplo, as marcas dos estudos pós-coloniais permitem incluir temas como o racismo e a visibilidade dessas subjetividades subalternas que não encontravam até agora os modos de representação discursiva. A teoria da interseccionalidade do gênero foi uma contribuição fundamental para pensar a relação entre gênero, raça e classe social (DAVIS, 1981).

Contudo, as contribuições do feminismo tornaram-se parte das ciências sociais nos chamados estudos de gênero. Essas integrações habilitaram novas vozes e visões críticas sobre o design como campo do estudo. Autoras como Judy Attfield (1989), Cheryl Buckley (1989) e Pat Kirkham (2000) foram as primeiras a denunciar a invisibilidade histórica das mulheres no campo do design. Também questionaram o legado do movimento moderno para a disciplina do design e a construção do cânone, especialmente em torno da retórica da neutralidade. Ou seja, elas criticam a produção de objetos sem refletir sobre a relação histórica e social que carregam. A partir da crítica feminista, tornou-se evidente que o cânone é concebido como um valor universal e neutro, denunciando, ao mesmo tempo, que é uma construção social que exclui outras 
intervenções, práticas e sujeitos femininos. Especificamente no campo do design, ele tem sido expressado, por exemplo, no lugar que ocupou o design têxtil, a ilustração, a caligrafia, as artes aplicadas e a moda. Ou seja, essas disciplinas foram subestimadas porque estão ligadas com o mundo doméstico/privado e o decorativo, aspectos que a lógica sexista tem descrito como sexo feminino em oposição ao público e racional, próprios do universo masculino (BUCKLEY, 1989).

Os discursos dominantes do design têm sido atravessados pelo modelo alemão da Escola Bauhaus e a perpetuação do cânone. Por conseguinte, colocar em crise o cânone implica, antes de tudo, debater sobre as relações de poder no campo do design e no social (POLLOCK, 1999).

No século XX, o movimento moderno estabeleceu para os homens as funções nas áreas do design relacionadas com a produtividade industrial, no entanto, as mulheres foram nomeadas para fazer as práticas associadas à domesticidade, como as artes decorativas, a joalheria, a ilustração, os têxteis e a cerâmica, entre outras. Como observou M. Valdivieso:

(...) o grande afluxo de mulheres que experimentaram a Bauhaus em sua criação foi perturbador para o diretor. Temendo que elas pudessem prejudicar as metas grandiosas da escola, Gropius recomendou em uma circular do Conselho de professores fazer uma seleção estrita, especialmente no que diz respeito aos "experimentos" desnecessários, e propunha enviar as mulheres, após o curso introdutório, à oficina de tecelagem ou à cerâmica. (VALDIVIESO, 1999, p. 247)

\section{À moda do gênero}

Não se pode ignorar o fato de que, desde a sua criação, especialmente no século XIX, o sistema de moda teve um papel muito significativo na objetificação das mulheres ocidentais. Em primeiro lugar, ele ajudou a fortalecer a naturalização da imaginação social que caracteriza o corpo feminino como um corpo bonito e ornamentado.

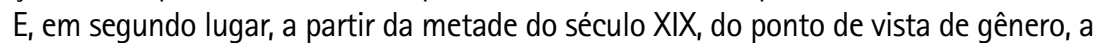
moda aumentou a divisão binária entre o feminino e o masculino. Ou seja, foram estabelecidos dois padrões binários nas formas de vestir: um para homens e outro para mulheres. Por um lado, ambos simbolizavam valores opostos, a roupa das mulheres devia conotar o sentido de sedução feminina, e este efeito não podia estar presente no vestuário masculino. Então, os trajes femininos tornaram-se mais complexos em termos de vestuário, tecidos e bordados. Por outro lado, os trajes masculinos sofreram o processo inverso por causa da simplificação dos modelos que os desmantelou de quase todo o elemento decorativo e ornamental.

0 traje feminino típico do século XIX marcava a silhueta e as formas dos corpos. A combinação de roupas com acessórios fizeram um estereótipo da beleza feminina, associada ao decorativo que, à primeira vista, é diferente do masculino.

Nesse sentido, podemos dizer que, na modernidade industrial, o vestuário teve um lugar muito significativo, envolvendo a classificação dos gêneros em termos binários com efeitos na regulação cultural das sexualidades. Desse ponto de vista, a moda pode ser concebida em diálogo com o dispositivo da sexualidade que falou M. Foucault (ZAMBRINI, 2013). Além disso, as modas se basearam no uso de roupas que impediam os movimentos corporais das mulheres. Isso consolidou a ideologia moderna que excluiu as mulheres da fase de produção e as posicionou como consumidoras passivas. Esses estilos de roupa também destacaram a distinção de classe social, porque nem todas as mulheres ficaram de fora do mundo do trabalho. Ou seja, o movimento do corpo impedido pela roupa era mais uma marca da posição social, pois se alijava dos modos de vestir das trabalhadoras, por exemplo, nas fábricas têxteis (MARTINEZ BARREIRO, 1998).

Como já foi dito, no século XIX, a cultura ocidental acrescentou, por meio da moda, padrões binários nas formas de vestir, o feminino e o masculino. Ambos simbolizam 
valores opostos: por um lado, o vestuário das mulheres deve denotar o significado da sedução e da feminilidade; por outro, os sentidos da sedução e o decorativo devem estar ausentes no traje masculino. Essa fase é chamada "a grande renúncia do século XIX", pois os valores do puritanismo da fase vitoriana e as alterações provocadas pela Revolução Industrial transformaram o comportamento social e as relações cotidianas. Desde o Renascimento até meados do século XIX, a história da moda mostra que tanto mulheres quanto homens podiam estar vestidos de forma extravagante. Nobres e burgueses lutavam pelo poder social também por meio das roupas até, aproximadamente, a década de 1830; depois, os valores puritanos e as mudanças provocadas pela Revolução Industrial reestruturaram o comportamento social e a lógica do vestir.

A figura da "grande renúncia" tornou possivel refletir sobre o significado simbólico e as implicações estéticas que teve, por um lado, a separação dos modos de vestuário entre homens e mulheres e, por outro, que os elementos decorativos já não faziam parte do traje masculino.

As roupas dos homens perderam suas funções ornamentais e privilegiaram a uniformidade como um atributo de decência e bom de vestir, mas, sobretudo, como um símbolo de masculinidade. Dessa forma, as roupas masculinas começaram a simbolizar a naturalização da identidade de gênero em oposição à identidade feminina, e vice-versa. Contudo, existe uma linha entre a ideologia do tempo em torno da heterossexualidade obrigatória e as normativas de apresentação do corpo e do vestuário binário (ZAMBRINI, 2010).

No entanto, com o passar do tempo, as modas mudaram em sintonia e diálogo com as mudanças políticas e sociais, que deram mais espaço e poder às mulheres². Porém, o percurso histórico nos ajuda a entender, pelo menos em parte, por que a roupa tem sido associada no presente com o feminino, e como isso manifesta hoje em dia certos preconceitos que sugerem a "feminização" dos atores que recriam o campo da moda e do têxtil. De alguma forma, isso favoreceu a legitimação social de outros campos, como o design industrial e o gráfico, ambos dominados por homens. Todavia, de acordo com M. Garone Gravier (2013), o design industrial e o gráfico não têm reconhecido corretamente o trabalho das mulheres na consolidação desses campos, situação que não é exclusiva das disciplinas de projeto, design e moda.

Até agora, temos peças de vestuário, como saia e gravata, ou cores, como rosa e azul. No imaginário coletivo, esses itens estão associados ao feminino e ao masculino de forma binária e exclusiva. Estudar moda é também pesquisar a construção social dos gêneros procurando entender como o olhar da sociedade vai mudando em relação ao que entendemos por masculino e feminino.

\section{Sem gênero}

Atualmente, na moda, está se expressando um forte processo de mudança social e cultural em relação à construção dos gêneros. Por exemplo, as passarelas mais importantes têm hoje modelos transgêneros, além do surgimento de tendências que borram os limites tradicionais do feminino e do masculino nas propostas do vestir. $\mathrm{Ou}$ seja, o foco não é mais a biologia para pensar as identidades, e essa mudança é significativa justamente porque rompe com a ideologia binária do século XIX e nos permite falar sobre identidades no plural (ZAMBRINI e IADEVITO, 2009). É uma transformação sociológica muito significativa, que supera todo um sistema de crenças (SAULQUIN, 2014). Ou seja, pôr em questão os principais sistemas normativos da modernidade industrial para dar espaço a novas formas sociais, nas quais o feminino e o masculino não se organizam em termos binários.

A presença de modelos transgêneros ${ }^{3}$, como A. Peijick ou Lea T, são exemplos dessa mudança cultural expressada no mundo da moda. Suas aparições nas passarelas e em revistas internacionais levantaram polêmica, mas não rejeição. Podem ser interpretadas como novas maneiras de se pensar os gêneros, mas também falam das novas experiências dos corpos. Ao mesmo tempo, as tendências das lojas "a-gender"4 ou "no gender" (sem gênero) são propostas do vestir que expressam o câmbio social em relação às novas maneiras de entender os gêneros, os corpos e as identidades 
sociais. 0 campo da moda fez essa mudança cultural ainda mais visivel, embora, hoje em dia, existam numerosas campanhas de moda que conceitualmente jogam com uma estética ambígua dos gêneros. Conscientemente ou não, muitos designers tornam visível a crise dos gêneros feminino e masculino entendidos em termos binários e tradicionais. 0 novo milênio traz para as sociedades ocidentais novas formas de entender os corpos, as identidades e os gêneros ${ }^{5}$. Isso também revolucionou e faz parte do mundo da moda.

\section{Considerações finais}

Neste trabalho, eu quis romper com certo senso comum que diz que as roupas são "naturalmente" coisas das mulheres. Temos ainda muitas restrições históricas e culturais que afetam a ordem dos gêneros e a reprodução das desigualdades sociais. Os gostos e as escolhas individuais não são apenas produtos de valores e códigos pessoais, mas também são permeados pelo contexto e por hierarquias sociais (BOURDIEU, 1993).

Nesse sentido, falar da moda e do design a partir de uma perspectiva de gênero pode não agradar às pessoas que passam por essas áreas porque, refletir sobre o gênero evidencia os mandatos culturais e sociais, a supervalorização de determinados temas e espaços, bem como a invisibilidade de outros. No entanto, refletir sobre as práticas do vestir através do olhar sociológico e de gênero pode ajudar no processo de mudança social no futuro. Dessa forma, o design pode dar boas ferramentas para a transformação cultural com propostas inovadoras e plurais sobre o corpo e os usos sociais da vestimenta. Por exemplo, podem ajudar a quebrar os estereótipos de gênero, além da estética e do consumo, em virtude da diversidade cultural e de gênero.

Este trabalho começou questionando por que as vozes dominantes do design e da moda são masculinas, além do fato de que foi a maioria das mulheres que recriou esse espaço. Eu propus uma breve história social do vestir que levou a pensar na consolidação do patriarcado no século XIX e na persistência da visão masculina de mundo que as próprias mulheres têm até hoje.

Longe de fechar a questão, este artigo procurou provocar reflexões sobre questões de gênero que são naturalizadas na vida diária. Quando falamos de moda e de design devemos saber que não são campos homogêneos, e que existem diferentes atores que os integram e trabalham para dar-lhes vida de forma pouco harmônica e desigual. Contudo, ajudar na conscientização das assimetrias de poder, muitas vezes não ditas, como o gênero, e romper os pontos de vista essenciais que cercam o mundo da moda e do design é também uma tarefa apropriada do campo acadêmico.

Mas também deixo aqui aberta a questão da ideia da falsa neutralidade no processo do design; questão esta que nos leva a pensar na herança do movimento moderno e do cânone no campo do design e já desenvolvida brevemente neste trabalho. Contudo, as referências feitas aos modelos transgêneros e às novas propostas do vestir "a-gender" ou "sem gênero" podem nos fazer refletir sobre essas temáticas. Por um lado, essas propostas na moda são expressão de uma mudança cultural mais profunda sobre a questão dos gêneros e das identidades no 0cidente; e por outro, paradoxalmente, se legitimam a partir dos discursos da criação de objetos neutrais e sem gênero. Ou seja, além do risco de propor uma leitura dos objetos e dos corpos como neutras, esses discursos já foram criticados pelo feminismo e pelos estudos de gênero a partir da denúncia da falsa neutralidade e de suas consequências ideológicas e políticas. Contudo, um dos maiores desafios atuais para o campo do design é superar os discursos e legados do movimento moderno e o pensamento binário sem recair em uma reprodução da falsa neutralidade. 


\section{NOTAS}

* Agradeço especialmente ao meu querido amigo o Prof. Carlos Augusto Martins por sua ajuda com o português.

[1] Por exemplo, o futurista Marinetti declarou, em seu manifesto escrito em 1909, que as mulheres não poderiam ter o valor, a coragem, nem a energia necessárias para criar o mundo novo. Contudo, os discursos principais do movimento moderno deixavam de fora as mulheres e estabeleciam os homens como os protagonistas da vida social (HERVÁS y HERAS, 2015).

[2] É importante apontar que as sociedades latino-americanas foram herdeiras, por causa do colonialismo e da imigração, dos principais padrões dominantes em torno da configuração social da beleza e da moda. Esse patrimônio está intimamente relacionado com o discurso e as representações visuais da modernidade industrial. Nesse sentido, falar de moda inevitavelmente é construir uma história com um forte viés eurocentrista.

${ }^{[3]}$ Para uma melhor referência da categoria transgênero pode-se consultar: ZAMBRINI, Laura, Práticas travestis: teorias y debates sobre corporalidades disruptivas. In: Revista Artemis, Dossiê Gênero y Sexualidades, n. 13, Universidade de Paraíba, João Pessoa, Brasil, 2012, pp. 42-61.

${ }^{[4]}$ A criação de "a-gender" das lojas Selfridges e de "no gender" de thecorner.com são alguns exemplos do design que tentam pôr em crise os modos de vestir binários.

${ }^{[5]}$ Os complexos debates sobre o sistema sexo e gênero nos termos binários são próprios das sociedades ocidentais, por exemplo, na İndia já falam em terceiro gênero.

\section{REFERÊNCIAS}

ATTIFIELD, Judith. Form/Female Follows Function/Male: Feminist Critiques of Design. In: Walker, J. Design History and the History of Design. Londres: Pluto Press, 1989, pp. 199-221.

BOURDIEU, Pierre. La distinción. Madrid: Taurus, 1993.

BOURDIEU, Pierre. La dominación masculina. Barcelona: Anagrama, 1998.

BUCKLEY, Cheryl. Made in Patriarchy: Theories of Women and Design - a Reworking. In: Design and Feminism: Re-visioning Spaces, Places and Every Things. Londres: University Press, 1999, pp. 109-118.

BUTLER, Judith. El género en disputa: el feminismo y la subversión de la identidad. Buenos Aires: Paidós, 2001.

DAVIS, Angela. Mujeres, raza y clase. Madrid: Akal, 1981.

ENTWISTLE, Joanne. El cuerpo y la moda: una visión sociológica. Barcelona: Paidós, 2002.

FOUCAULT, Michel. Historia de la sexualidad. V. I: La voluntad del saber. Buenos Aires: Siglo XXI Editores, 2003.

GAMBA, Susana. Diccionario de estudios de género y feminismos. Buenos Aires: Biblos, 2007.

GARONE GRAVIER, Marina. Los designios de Eva: el género en la identidad del diseño latinoamericano. In: Revista_180, n. 24. México: Universidad Diego Portales, 2013, pp. 1-35.

HERVÁS Y HERAS, Josenia. Las mujeres de la Bauhaus: de lo bidimensional al espacio total. Buenos Aires: Diseño Editorial, 2015.

KIRKHAN, Pat. (Ed.) Women Designers in the USA, 1900-2000: Diversity and Difference. Nova York: Yale University Press, 2000.

LAMAS, Marta. Usos, dificultades y posibilidades de la categoria género en La Ventana. Revista de Estudios de Género, n. 1. Guadalajara: Centro de Estudios de Género de la Universidad de Guadalajara, 1995, pp. 327-344.

MARTÍNEZ BARREIRO, Ana. La moda en las sociedades modernas. Madrid: Tecnos, 1998.

POLLOCK, Griselda. Differencing the Canon: Feminist Desire and the Writing Ofart's Histories. Londres: Routledege, 1999.

SAULQUIN, Susana. Política de las apariencias: nueva significación del vestir en el contexto contemporáneo. Buenos Aires: Paidós, 2014. 
SCOT, Joan. Las mujeres y los derechos del hombre: feminismo y sufragio en Francia, 1789-1944. Buenos Aires: Siglo XXI, 2012.

VALDIVIESO, Mercedes. Retrato de grupo con una dama: el papel de la mujer en la Bauhaus. In: Historia y Teoría del Arte, n. 6 (2000), pp. 61-74. Bogotá. Universidad Nacional de Colombia, 2014.

ZAMBRINI, Laura. Modos de vestir e identidades de género: reflexiones sobre las marcas culturales sobre el cuerpo. In: Revista de Estudios de Género Nomadías, n. 11. Santiago: Universidad Nacional de Chile, 2010, pp. 130-149.

El género como metáfora: narrativas sobre travestis en prensa digital argentina (20042009), revista Sociedad y Economía, n. 24. Cali: Universidad del Valle, 2013, pp. 143-158.

Prácticas travestis: teorias y debates sobre corporalidades disruptivas. In: Revista Artemis, Dossier Genero y Sexualidades, n. 13. João Pessoa: Universidade da Paraíba, 2012, pp. 42-61.

Laura: IADEVITO, Paula. Feminismo filosófico y pensamiento post-estructuralista: teorías y reflexiones acerca de las nociones de sujeto e identidad femenina. In: Sexualidad, Salud y Sociedad, Revista Latinoamericana, CLAM, n. 1. Rio de Janeiro: Universidade Estadual do Rio de Janeiro, 2009, pp. 162-180. 